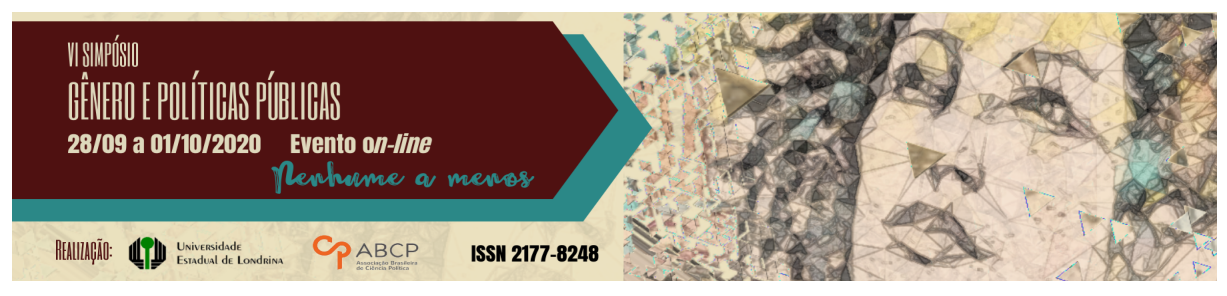

\title{
Direitos sexuais e direitos reprodutivos: a escuta enquanto produtora de saúde mental às mulheres-mães
}

\author{
Thais Gomes de Oliveira ${ }^{1}$
}

\section{Resumo}

Este trabalho apresenta enquanto temática a saúde mental de mulheres que são mães, trazendo aproximações entre campos da psicologia social, da assistência social e de uma prática clínica. Surge no campo de problematizações entre políticas socioassistenciais e as maternidades, campo este ampliado - neste trabalho - para uma discussão acerca de grupos de escuta que são compostos por mulheres e que acontecem em Porto Alegre/RS. Trata-se de um recorte de pesquisa de mestrado e é um ensaio fundamentado em metodologia feminista que se vale da ficcionalização de histórias a partir de diferentes encontros no contexto da pesquisa. Objetiva propor discussão a partir de algumas práticas de escuta enquanto invenção de modos de cuidado que estejam inseridos em seara ampliada na garantia de direitos sexuais e de direitos reprodutivos dessas pessoas interpeladas enquanto mulheres e interpeladas enquanto mães.

Palavras-chave: psicologia social; metodologia feminista; grupos de escuta.

\begin{abstract}
This paper presents as its theme the mental health of women who are mothers, bringing together the fields of social psychology, social assistance and clinical practice. It comes about among problematizations between social assistance policies and motherhoods, the latter being amplified in this paper for a discussion about listening groups, which are composed by women and take place in Porto Alegre/RS. The paper is a piece of a master's research and an essay based on feminist methodology that uses fictional stories that stem

1 Universidade Federal do Rio Grande do Sul; Psicóloga/UFRGS. Mestranda em Psicologia Social e Institucional/UFRGS - Bolsista CAPES. Extensionista da Clínica de Atendimento Psicológico/UFRGS. E-mail: thais_gomes.oliveira@hotmail.com.
\end{abstract}

GT 11 - Gênero, políticas de desenvolvimento e combate à pobreza 
from various encounters in the research context. Its objective is to propose a discussion from listening practices to make up caring means that are placed in an amplified field on the guarantee of sexual and reproductive rights while women and while mothers.

Keywords: social psychology; feminist methodology; listening groups.

\section{Introdução}

No campo de investigações acerca da generificação de políticas do cuidado e, mais especificamente, da responsabilização de mulheres por tarefas na seara da reprodução social e da vida, as políticas públicas socioassistenciais são campo profícuo para discussão e problematização. A centralidade em corpos mulheres e em exercícios de maternidades proposta pela Política Nacional de Assistência Social, como investigado por autoras como Cássia Carloto e Silvana Mariano (2008) e outras pesquisadoras de diferentes campos, encaminha a presente investigação para o campo de mulheridades e maternidades, compondo com intervenções de grupos de escuta como uma prática feminista neste momento de atualização de práticas de cuidado surgidas a partir da pandemia causada pelo novo coronavírus. No campo dos cuidados, os direitos sexuais e os direitos reprodutivos se tornam um dos eixos problemáticos em que podemos perceber a constante produção de uma inteligibilidade de gênero cisheteronormativa e reprodutora, atravessada por lógica heterocolonial: sabemos que mulheres são impelidas de funções de cuidado e de proteção, que são algumas vezes responsabilizadas pela reprodução social e da vida e que, sob as matrizes de gênero de um sistema patriarcal, têm sido subalternizadas.

A partir da Psicologia Social e em diálogo com diferentes áreas do conhecimento, a saúde mental de mulheres que são mães se constitui enquanto foco de discussão neste texto que é produzido enquanto recorte de pesquisa de mestrado vinculado à Universidade Federal do Rio Grande do Sul (UFRGS). Portanto, a pesquisa recortada aqui se desenvolve em dois campos em que atuo enquanto psicóloga e pesquisadora: a Clínica de Atendimento Psicológico da UFRGS e a 
Clínica Feminista na Perspectiva da Interseccionalidade. Ambos prestam serviço à comunidade em situação de vulnerabilidade socioeconômica e têm escutado diferentes mulheres em sofrimento em decorrência da agudização da convivência doméstica e da constante diminuição nas redes de apoio.

Nesse campo problemático, buscamos dialogar acerca da seguinte pergunta: Como grupos de escuta podem configurar práticas de cuidado que estejam inseridas na seara ampliada de garantia de direitos sexuais e de direitos reprodutivos dessas pessoas interpeladas enquanto mulheres e enquanto mães? Para isso, estaremos em diálogo com autoras do campo dos estudos feministas, de autoras que estejam pensando a atualização da quarentena para a vida de mulheres e de autoras do campo da saúde mental em interlocução com estudos de gênero. Propomos a discussão em três eixos, a saber: i. Pluralizando contares feministas: metodologia ii. Ressituando a intervenção: grupos online de escuta; iii. Feminismo, interseccionalidade, clínica e iv. Direitos sexuais e direitos reprodutivos: que lugar pode ter a escuta? Inicialmente, apresentamos a história de Roberta ${ }^{2}$

Roberta vive com seus filhos, filhos meninos. É junho de 2020 na vida de Roberta, mulher, negra, mãe, filha. Roberta tem recebido o auxílio emergencial, é usuária da rede socioassistencial de um município da região metropolitana de Porto Alegre. Morava de aluguel, precisou mudar de casa, ela e os filhos. Não trabalha atualmente, e nem sente que dá, já que os filhos passam o dia em casa com ela. O maior já ia pra escola e pro Serviço de Convivência e Fortalecimento de Vínculos, o menor já tava na creche. A vida de Roberta tem sido ajudar em algumas atividades dos filhos e ficar com o companheiro que conseguiria lhe oferecer um espaço onde morar. Ela não conversa muito com muitas pessoas durante a pandemia, tem vontade mas a vida tem estado complicada. Ela gostava muito de trabalhar fora quando pôde, o espaço de trabalho era como refúgio, até

2 A história apresenta é inspirada no trabalho de escuta de mulheres. O nome Roberta é uma invenção, tal qual é a história em si. Trata-se de uma ficção de invenção híbrida. 
do longo trajeto de ônibus gostava muito. Roberta é uma pessoa implicada na comunidade onde vive, aposta na vida coletiva, nas organizações de bairro. Sabe que os direitos das mulheres têm sido dificultados agora, que a escola faz falta. Também gosta de participar da alfabetização do filho mais velho. Ela pergunta sobre como vai poder voltar a trabalhar fora e se aproximar de novo das pessoas de quem gosta e que acabou não vendo mais.

\section{Pluralizando contares feministas: metodologia}

Inicio com uma provocação às vistas desse contar metodológico: "a neutralidade não nos cabe. Pois sim, a escrita tem sentimentos. Sim, o texto é corporificado" (FAVERO, 2020, p. 19).

Este é um ensaio teórico-metodológico que é constituído a partir da ética de pesquisa proposta por Donna Haraway (1995). Os conhecimentos situados são ferramenta metodológica em que a pessoa pesquisadora é radicalmente implicada naquilo que produz: busco situar a escrita em primeira pessoa do singular, localizar as epistemologias com as quais dialogo durante e pesquisa e estar constantemente parte daquilo que produzo. Sigo as pistas de Sofia Favero (2020, p. 13) em seu texto Por uma ética pajubariana: "se a vivência é uma sujeira acadêmica, decido deixar uma mancha em meus escritos". Busco evidenciar a localização da produção de conhecimento, aliada com a objetividade feminista proposta por Haraway e também defendida por Favero.

Neste texto, estaremos dialogando às voltas da escuta enquanto prática feminista e das possibilidades de promoção de saúde mental a mulheres que são mães. Este é um recorte de pesquisa de mestrado em andamento, cabe situar. $\mathrm{O}$ feminismo é aqui entendido enquanto uma prática que é "de todo mundo", como defendido por bell hooks (2019): não é totalizado aos sujeitos interpelados mulheres, não pertence a ninguém (DAVIS, 2018). Ou seja, aqui, falamos de produção de direitos sexuais e direitos reprodutivos para mulheres enquanto um recorte de pesquisa, mas sabemos que a prática feminista está além dos 
sujeitos mulheres. Sigo atenta ao convite de Paul Preciado (2019) para que os movimentos feministas, e outros ainda, que produzem narrativas de vozes subalternizadas estejam integrados em um processo crítico de invenção de formas outras de subjetividades nãobinárias para que não reiterem lógicas coloniais e patriarcais.

Enquanto metodologia feminista em diálogo com a produção de conhecimento no campo da psicologia social, busco a radicalidade da desnaturalização. Não há natureza a buscarmos, e sim caminhos que são constantemente produzidos e, por vezes, repetidos. Sujeitas mulheres têm sido responsabilizadas mais largamente por tarefas relativas à economia dos cuidados (IPEA, 2016) e é a partir da psicologia social, com a noção de que nada é natural (NEVES, 2008) e a partir de metodologia feminista, que propõe o questionamento de coisas que parecem naturalmente unidas (DAVIS, 2018) que sigo relativizando tais naturalizações que reiteram os espaços de vida de mulheres enquanto privatizados.

No trabalho com os grupos de escuta, a equipe propõe um momento online e virtual, de modo que "entramos" nas casas de mulheres e as escutamos contar suas experiências de vida: o fazemos sabendo que há um fenômeno de privatização da vida de mulheres, que estariam fadadas à inventada "vida privada", como apontado pelas autoras Campos e Mioto (2010). Assim, buscamos politizar experiências cotidianas, lembrando que para o contar de modos de vida não hegemônicos, a escuta e a narratividade são importantes ferramentas.

Questionamos a hegemonia dessa invenção de que a vida das mulheres se restringiria à casa, enquanto as escutamos em situação de isolamento doméstico, apostando na produção de narrativas. Confrontar histórias hegemônicas a partir da pluralização e atualização de formas de contar o mundo (MENESES, 2008) é tarefa da qual nos ocupamos através da escuta. É assim que opto neste texto por trabalhar a partir da metodologia feminista e a partir de metodologia de ficcionalização de histórias. Busco escrever este texto a partir de narrativas que se admitem poéticas, que não buscam a estilística de 
ficções documentais, que afirmam "outras possibilidades de construção do saber para além do verdadeiro e do falso" (COSTA, 2014 , p. 555). Sigo de acordo com o autor quando propõe que

Desvencilhar-se dos preceitos da escrita que buscam a neutralidade-objetividade e tomar a poética como estratégia, é assumir a materialidade da palavra, a concretude ativa da experiência da escrita e permitir que as sutis virtualidades das preensões contagiem a escrita, sem as pretensões cartesianas de negar às aparências em prol de essências pressupostas (COSTA, 2014, p. 558).

Essa é Roberta, uma produção híbrida que evidencia o que colocamos em discussão: uma pessoa interpelada enquanto mulher, enquanto negra, enquanto mãe - vivendo em um Brasil pandêmico em 2020, inventando proteção social, buscando a Renda Básica Emergencial, subvertendo formas cotidianas de violação enquanto produz formas de vida. Mas, além disso, é uma produção narrativa inventiva que extrapola a inteligibilidade de conhecimento cotidiano que se supôs, outrora, ter.

\section{Ressituando a intervenção: grupos online de escuta}

Práticas e estudos feministas vêm reformulando perguntas no campo clínico. O campo que se institui no eixo saúde mental e gênero tem assumido o lugar de existência e de produção de sofrimento que se relaciona com como é interpelado nas normativas de gênero (ZANELLO, 2018). A fim de estabelecer os pontos que seguirão sendo trabalhados conceitualmente, é importante situar que os rumos da pesquisa em questão estão em constante redesenho: o cenário pandêmico atualiza e acirra formas de viver, de ser mãe, de ser mulher, de ser; de garantir ou promover direitos, construir redes de apoio, escutar e intervir (muito do que cabe a quem se ocupa de trabalhos psi). Sabemos, portanto, que as (im)possibilidades da escuta enquanto intervenção para ampliação de direitos sexuais e de direitos reprodutivos estão em tempo de reconfiguração. 
No campo que articula a produção generificada de acesso à saúde e produção de saúde mental, mesmo que gênero seja um importante determinante social, as pesquisas e estudos são ainda incipientes (ZANELLO, 2018). É nesse cenário que o projeto de extensão acadêmica intitulado "Clínica Feminista na Perspectiva da Interseccionalidade" é repensado. Iniciada a mandatória do confinamento doméstico, as demandas de apoio e de escuta em saúde mental aumentam - ao passo que aumentam os dados que afirmam que as mulheres têm sofrido ainda mais violência. É através de consciência interseccional em atuação feminista que a equipe busca fundamentar suas ações. E foi a partir do início do cenário pandêmico que a equipe envolvida no projeto é interpelada por necessidade de mobilização no atual contexto de crise sanitária - ou humanitária. Os índices de violência patriarcal ${ }^{3}$ estiveram aumentando drasticamente $^{4}$ e é diante desse cenário que iniciamos os grupos de escuta entre mulheres.

Enquanto intervenção no campo da saúde-mental para mulheres em situação de pobreza, atentamos para o fenômeno de feminização da pobreza e da inclusão social (MEYER et al, 2014) e de feminização de patologias no campo da saúde mental (ZANELLO, 2018). Responsabilizadas pela manutenção dos lares, cuidados de filhas/os, cuidados domésticos e de demais membros das famílias, a situação pandêmica eleva exponencialmente o trabalho de mulheres ao passo que acirra seus acessos a direitos. Na mesma direção, as casas se tornam espaços ainda mais solitários.

A casa enquanto instituição é um espaço contraditório, que pode ser hostil e muitas vezes é violento às mulheres, enquanto que, durante o período de distanciamento social, torna-se fundamental para a proteção social. Nesse cenário, mulheres têm estado muitas vezes

\footnotetext{
3 bell hooks estende a noção de violência doméstica quando afirma que violência patriarcal está além da violência cometida por homens contra mulheres em ambiente doméstico - é possível que esta incorra sob as crianças, sob os mais velhos - e todas/os podem ser autoras/os, visto a complexidade dos sistemas de opressão (hooks, 2019).

4 Ver mais em: https://g1.globo.com/monitor-da-violencia/noticia/2020/09/16/osefeitos-colaterais-da-pandemia-sobre-a-vida-das-mulheres.ghtml. Acesso em: 26 out. 2020.
} 
interpeladas pelos sistemas estruturais de opressão que estão agudizados no cenário pandêmico devido à fragilização da convivência presencial - a ausência das escolas e a precarização dos serviços de saúde e assistência social exige medidas de promoção de saúde no campo da saúde mental como possível garantia de direitos.

$\mathrm{Na}$ aposta de que o grupo enquanto dispositivo é uma estratégia de escuta que coletiviza ao invés de individualizar, propomos essa clínica que atua em tempos pandêmicos na produção de escuta. Escuta enquanto proposição multidisciplinar, que atua com mulheres em situação de pobreza, em alguma situação de violência de gênero, e que se propõe a inventar direitos. Nesse cenário, neste texto, pensamos nos atravessamentos das maternidades e na produção possível de direitos sexuais e direitos reprodutivos para mulheres que são mães.

Na sequência, busco adensar a produção de interlocuções nos campos do gênero que envolvam feminismo, interseccionalidade e clínica - produzindo ponte com o campo dos direitos reprodutivos. Essas pontes, nada ingênuas, são propostas nessa metodologia feminista.

\section{Feminismo, interseccionalidade, clínica}

A população que mais vezes alvo do projeto de desigualdade social é negra, pobre e periférica. No cenário pandêmico, há um atravessamento que intensifica os modos de análise da produção de vulnerabilidade e, podemos saber, a população que mais largamente compõe o cenário ampliado da economia do cuidado e que tem morrido mais é também majoritariamente negra e pobre. A proteção social básica e o acesso à saúde pública são medidas básicas - previstas na constituição - para a garantia de direitos humanos básicos. Nesse cenário relativo à proteção social, sujeitas mulheres estiveram sendo interpelados de diferentes maneiras para uma concepção de cuidado formal ou informal: em trabalhos domésticos, educacionais, socioassistenciais etc. De forma que o cenário dos cuidados avança 
todo este campo, das caixas de supermercado às empregadas domésticas que são, neste Brasil marcado pelo colonialismo, mulheres negras. Esse fenômeno foi discutido e ironizado por Lélia Gonzalez (1984) que defende que, no Brasil, a verdadeira mãe é a mãe-preta - a quem chama de mucama.

As mulheres são as principais responsáveis por tarefas colocadas enquanto da esfera doméstica e são, ainda, as responsáveis pela manutenção das famílias no contexto brasileiro ${ }^{5}$. As políticas socioassistencias exemplificam essa situação em termos da letra da lei, visto que essas políticas se constroem tendo como público-alvo mulheres, sobretudo mulheres que são mães (OLIVEIRA; BATTISTELLI; CRUZ, 2018), no desenvolvimento de suas ações para a garantia de direitos. Nesse cenário feminizado, a interlocução entre pesquisa em psicologia social e pesquisa feminista é caminho para a articulação que questiona a naturalização da esfera dos cuidados.

Tal naturalização essencialista revela seus efeitos marcadamente. A partir de olhar crítico através dos articuladores estruturais de raça, de classe e de gênero se vê que às mulheridades e às maternidades negras e pobres as subalternizações são agravadas. A interseccionalidade é um conceito cunhado por Kimberlé Creenshaw e é uma categoria analítica que complexifica o imbricamento entre diferentes sistemas de opressão. No contexto da pandemia, o cuidado e a proteção social são elevados ao centro do debate por muitos segmentos e é a partir de ética feminista com consciência interseccional que o campo das maternidades produz questionamentos. É fundamental considerarmos que as mulheres não produzem experiência única e que existem diferenças - que muitas vezes são abismo - em suas vidas. Os estudos feministas e de gênero têm tentado situar as desigualdades vividas entre mulheres enquanto fator determinante para o acesso a direitos e para execução do cuidado (IPEA, 2016).

5 Casas consideradas chefiadas por mulheres, majoritariamente solteiras, chegam a $42 \%$, segundo dados do IBGE (2019). 
Retomo a produção inicial - visto que Roberta é ficção que evidencia os imbricamentos entre maternidades, pobreza, racismo. Roberta é uma produção construída na pesquisa que nos auxilia na construção de que a privatização da vida é uma invenção que acirra direitos e que, ao escutar as casas e os movimentos cotidianos, podemos agir na produção de saúde mental em tempos pandêmicos. Ao passo que, em termos da produção de conhecimento, o olhar generificado e racializado para a produção de saúde mental busca produzir rupturas em formas hegemônicas e normativas de intervenção.

\section{Direitos sexuais e direitos reprodutivos: que lugar pode ter a escuta?}

É nesse campo problemático que busco elevar a proposição de grupos de escuta como forma de invenção de redes de apoio que, para mulheres que se ocupam do cuidado de crianças, pode agir na seara da garantia de direitos reprodutivos em noção ampliada. Os direitos reprodutivos são direitos humanos básicos e promulgados na Conferência do Cairo, no ano de 1994 (BRASIL, 2005) e incluem a esfera de reprodução social e da vida. Se origina enquanto conceito a partir de movimentos feministas na luta por reconhecimento de direitos das mulheres em relação à sexualidade e a reprodução (CARLOTO; DAMIÃO, 2018). Nesse campo, cabe perguntar: é possível pensarmos que, na seara da reprodução, as políticas que envolvem o cuidado de crianças podem estar atreladas às políticas de direitos reprodutivos? As escolas e creches têm estado nesse lugar que promove possibilidades outras de vida para tantas mulheres que são mães (VENTURA, 2009) e sabemos que, agora, a ausência das mesmas causa um espaço esvaziado na vida dessas mulheres.

O exercício de escuta grupal a que nos propomos objetiva coletivizar questões. Como para Roberta, questões às voltas do cuidado de crianças têm afetado diferentemente tantas mulheres a quem escutamos. É nessa aposta que buscamos, durante os grupos, evidenciar a politização de fenômenos cotidianos - falando sobre 
diferentes violências, sobre diferentes formas de vida, sobre diferentes efeitos do cenário pandêmico na vida de cada uma das mulheres.

O cuidado tem sido centralizado à casa - de forma que se focaliza ainda mais às famílias e às mulheres que são mães a responsabilização pela proteção social. No país, a chamada orientação "familista" na proposição de políticas têm sido debatido amplamente. Retomo a produção das autoras Campos e Mioto quando perguntam onde se ancora o caráter familista na política social visto que, há anos, percebemos uma mudança nas organizações familiares. É considerando essa produção centralizada na família e em mulheres que são mães que buscamos coletivizar narrativas de experiências às voltas dos cuidados como forma de promoção de saúde mental.

No Brasil, atualmente, temos visto um forte ataque às políticas de direitos reprodutivos. A chamada ofensiva antigênero é entendida como fenômeno transnacional, afixado no Brasil nos últimos anos, mas com origem nos anos de 1990 a partir de movimentos de extrema direita ocorridos no Vaticano e em políticas institucionais estadunidenses (CORRÊEA, 2018). Desde então, espalha-se em termos globais o debate moralizado e fundamentalista nessa corrente organizada que se fortalece atualmente na Europa e na América Latina. As autoras Corrêa e Petchesky em 1996 já alertavam sobre o que se contesta da noção de direitos sexuais e de direitos reprodutivos e que entre os que discordam do conceito, estão os religiosos fundamentalistas. É diante desse cenário que estamos colocadas hoje, seria impossível deixar de mencionar: o governo atual tem cada vez mais subalternizado a questão dos direitos reprodutivos. Enquanto proposição de pesquisa e de intervenção, a defesa desses direitos aqui acontece através dos grupos de escuta e do espaço de circulação da fala para mulheres em situação de vulnerabilização.

\section{Considerações Finais}

A pesquisa feminista se estende a uma Clínica Feminista? Grupos de escuta entre mulheres podem estar situados e localizados 
diante da problemática da fixidez das identidades? Mulheres que são mães poderiam - a partir de grupos de escuta - encontrar acessos a direitos no campo da saúde mental? No risco de um texto mais perguntador do que detentor de respostas, este texto esteve às voltas de pontes consideradas pertinentes no campo da saúde mental em produção situada, generificada, racializada e atuante com população muitas vezes vulnerabilizada - ainda mais no contexto pandêmico.

O campo da escuta em grupo, promovida através de projeto de extensão acadêmica vinculado à UFRGS é problematizado neste texto através de recorte da pesquisa de mestrado em andamento da autora: as aproximações entre assistência social e as maternidades levaram ao desencadeamento do cenário pandêmico enquanto campo atualizado para esta discussão. A saúde mental se tornou foco de um grupo multidisciplinar que se lançou à escuta online como forma de combater violências de gênero e promover práticas de saúde mental e, nesse contexto, essa pesquisa buscou discutir acerca dos direitos sexuais e dos direitos reprodutivos - tão atacados no atual governo e no contexto da pandemia no Brasil.

Seguimos as pistas de Debora Diniz 6 quando afirma que, em epidemias e pandemias, a saúde reprodutiva deve ser o centro das ações de combate e de promoção de saúde. Do campo da psicologia social, os grupos de escuta se tentam intervenção feminista com consciência interseccional e que agem diretamente no acesso à saúde mental e informação de sujeitos interpelados mulheres. É assim que inventamos uma prática feminista de rede de escuta e uma pesquisa feminista que busca a constante problematização e desnaturalização da ficção mulher.

\section{Referências}

6 Disponível em: https://azmina.com.br/reportagens/debora-diniz-e-hora-do-stfresponder-o-que-significa-uma-epidemia-para-a-vida-das-mulheres/. Acesso em: 30 ago. 2020. 
BRASIL. Ministério da Saúde. Secretaria de Atenção à Saúde. Departamento de Ações Programáticas Estratégicas. Área Técnica de Saúde da Mulher. Direitos Sexuais e Direitos Reprodutivos: uma prioridade do governo/Ministério da Saúde, Secretaria de Atenção à Saúde, Departamento de Ações Programáticas Estratégicas- Brasília: Ministério da Saúde, 2005. Disponível em: http://bvsms.saude.gov.br/bvs/publicacoes/cartilha_direitos_sexu ais_reprodutivos.pdf. Acesso em 11 de abril de 2020.

CAMPOS, Marta Silva; MIOTO, Regina Célia Tamaso. Política de Assistência Social e a posição da família na política social brasileira. Revista SER Social, Brasília, n. 12, p. 165-190, 2010.

CARLOTO, Cássia Maria; DAMIÃO, Nayara André. Direitos reprodutivos, aborto e Serviço Social. Serv. Soc. Soc., São Paulo, n. 132, p. 306-325, maio/ago. 2018.

CARLOTO, Cássia Maria; MARIANO, Silvana Aparecida. A Família e o Foco nas Mulheres na Política de Assistência Social. Revista Sociedade em Debate, Pelotas, n. 14, v. 2, p. 153-168, 2008.

CORREAA, Sonia; PETCHESKY, Rosalind. Direitos sexuais e reprodutivos: uma perspectiva feminista. PHYSIS: Revista Saúde Coletiva, Rio de Janeiro, v. 6, n. 1-2, p. 147-177, 1996.

COSTA, Luís Arthur. O corpo das nuvens: o uso da ficção na Psicologia Social. Fractal, Rev. Psicol., v. 26, n. esp., p. 551-576, 2014.

DAVIS, Angela. A liberdade é uma luta constante. São Paulo: Boitempo, 2018.

FAVERO, Sofia. Por uma ética pajubariana: a potência epistemológica das travestis intelectuais. Equatorial, Natal, v. 7, n. 12, jan./jun. 2020.

HARAWAY, Donna. Saberes localizados: a questão da ciência para o feminismo é o privilégio da pesquisa parcial. Cadernos Pagu, n. 5, p. 07-41, 1995.

hooks, bell. Ensinando a transgredir: a educação como prática da liberdade. São Paulo: Editora WMF Martins Fontes, 2017.

hooks, bell. O feminismo é para todo mundo: políticas arrebatadoras. Rio de Janeiro: Rosa dos Tempos, 2019a.

IPEA - Instituto de Pesquisa Econômica Aplicada. Economia dos cuidados: marco teórico-conceitual. Rio de Janeiro: Ipea, 2016. 
MENESES, Maria Paula. Outras vozes existem, outras histórias são possíveis. Niterói: Grupalfa/UFF, 2008.

MEYER, Dagmar Estermann; KLEIN, Carin; DAL'IGNA, Maria Claudia; ALVARENGA, Luiz Fernando. Vulnerabilidade, gênero e políticas sociais: a feminização da inclusão social. Revista Estudos Feministas, Florianópolis, v. 22, n. 3, p. 885-904, 2014.

OLIVEIRA, Thais Gomes de; BATTISTELLI, Bruna Moraes; CRUZ, Lílian Rodrigues da. A função protetiva das famílias e a responsabilização das mulheres-mães: um estudo sobre a matricialidade sociofamiliar na Política de Assistência Social. Simpósio Gênero e Políticas Públicas, V., Londrina, 2018. Anais [...]. Londrina, 2018.

VENTURA, Miriam. Direitos Reprodutivos no Brasil. Brasília: UNFPA, 2009.

ZANELLO, Valeska. Saúde Mental e Gênero: Cultura e processos de subjetivação. Curitiba: Appris, 2018. 